\title{
Facilitating Additive Manufacturing Engagement and Outreach
}

\section{Dr. Ranjeet Agarwala, East Carolina University}

Ranjeet Agarwala serves as a Teaching Instructor in the Department of Technology Systems at East Carolina University. He received his Bachelor of Science in Mechanical Engineering in 1997 from Bangalore University and Masters of Science in Mechanical Engineering from Texas A\&M University-Kingsville in 2000. He received his PhD in Mechanical Engineering from North Carolina State University in 2014. He has about 15 years of university teaching, industry, and industry consulting experience. Since 2001 he has taught courses in Engineering Graphics, 3D Printing, GD\&T, Electro-Mechanical Systems, Statics and Dynamics, Thermal and Fluid Systems, Controls and Engineering Measurements. His research interests are in the area of advanced manufacturing, exploration of 3D Printing as an innovation, engagement, and outreach tool, applications of 3D printing in multi-disciplinary areas such as healthcare and robotics, and in the renewable energy sector. He is married with two daughters and lives in the state of North Carolina.

\section{Dr. Robert A. Chin, East Carolina University}

Robert A. "Bob" Chin is a full professor in the Department of Technology Systems, College of Engineering and Technology, East Carolina University, where he has taught since 1986. He is the current director of publications for the Engineering Design Graphics Division and the editor for the Engineering Design Graphics Journal. Chin has also served as the Engineering Design Graphics Division's annual and mid-year conference program chair, and he has served as a review board member for several journals including the EDGJ. He has been a program chair for the Southeastern Section and has served as the Engineering Design Graphics Division's vice chair and chair and as the Instructional Unit's secretary, vice chair, and chair. His ongoing involvement with ASEE focuses primarily on annual conference paper presentation themes associated with the Engineering Design Graphics, the Engineering Technology, and the New Engineering Educators Divisions and their education and instructional agendas. 


\section{Facilitating Additive Manufacturing Engagement and Outreach}

\section{Introduction}

In addition to delivering instruction to students on the technical dimensions of additive manufacturing, engineering technology can and some suggest must play a role in delivering instruction on additive manufacturing's role in stimulating economic development, regional transformation, and domestic competitiveness. That is, the technology must be brought out of the lab and made accessible to those who have or can potentially have a role to play in the political and economic process ${ }^{1,2}$.

In spring of 2014, an initiative was launched to improve accessibility to additive manufacturing. This engagement and outreach effort not only focused on internal outreach to promote awareness within a general population but also to the general public. During the summer, an additive manufacturing workshop was completed by selected members of a general population.

In the fall of 2014, industrial grade additive manufacturing equipment was taken out of a lab setting and deployed to a more public facility and one in which members of the community would have greater accessibility. In addition, two more diverse subsets of the community's population received instruction and training on the equipment and technology.

At present, key is the sustainability of the engagement and outreach initiatives. That is how can these engagement and outreach initiatives be developed further and matured ecologically, economically, politically, and culturally. The literature is rich with models that can be deployed. These models include initiatives that pair up selected advocates and other personnel with external constituents from industry, innovation hubs, non-profits, and academic institutions. This initiative has also begun exploring opportunities to deploy additive manufacturing "vending machines" as part of greater community engagement model for stimulating economic development, regional transformation, and domestic competitiveness.

\section{Accessibility to Additive Manufacturing}

In academic communities, accessibility to 3D printing, while it is branching out, is generally limited to selected segments of the population. Deploying additive manufacturing by way of 3D printing in academic settings has the potential to contribute to sustaining this growth, expanding diversification, and stimulating economic development and domestic competitiveness.

Studies have reported on the use of 3D printing services as an effective engagement and outreach tool by integrating their technology with university facilities that are constantly and actively engaged with its community. Ramaley and Zea recommend using 3-D digital printing as a tool to foster engagement and learning ${ }^{3}$. At the same time, however, they have expressed reservations due to limitations posed by the exorbitant costs associated with 3D printing technology at that that time-2005.

Since 2005 though, the costs associated with 3D printing has fallen and many forms and a variety of machines are available. Because of this, there has been a greater effort to use 3D 
printing as an engagement and outreach tool. Hoy examined the concept of using the library for teaching 3D printing concepts to their patrons as they might for computers, photocopiers, and the internet ${ }^{4}$. As well, he has proposed expanding the offering of traditional 3D printing to medical applications. Scalfani has reported on the efforts of the University of Alabama libraries to facilitate an open access 3D printing studio ${ }^{5}$. The studio users incorporate these services into class projects, research, and instruction. Scalfani has also recommended the deployment of the 3D studio in a visibly open area in their library. Colegrove reported findings from the University of Nevada, Reno (UNR) ${ }^{6}$. He indicated that the services offered by the campus library were substantial and cut across numerous disciplines. He reported that cross-disciplinary users quickly adopted the 3D printing services offered by the UNR library and that the new 3D printers were operating at or near capacity during their first year of deployment. He also reported that anecdotal observations suggested that the academic communities' access to these services empowered deeper engagement with the construction of knowledge. Pryor described the 3D printing service at the Southern Illinois University Edwardsville's Lovejoy library ${ }^{7}$. He reported that their experience of the 3D printing service was a "mixed bag". While there was widespread excitement about the potential, the usage numbers were low. He recommended that a library looking to implement such a service establish metrics for success.

In an attempt to facilitate engagement and outreach, the authors used 3D printing as the means and developed and deployed several initiatives. These initiatives included the development and deployment of short and long versions of 3D printing workshops, identification of potential surplus technology and its deployment, and collaboration with campus library to offer 3D printing services. To further foster engagement and outreach opportunities to deploy additive manufacturing, additive manufacturing "vending machines" were examined as part of greater community engagement model. Deploying these machines at strategic locations across campus has now become part of the vision.

\section{A 3D Printing Event}

During the spring and summer of 2014, a three-day 3D printing event was developed and deployed. The purpose of this event was to introduce from 8-10 selected administrators, staff, and faculty members to 3D printing. Upon completion of the event, it was hoped that participants would be knowledgeable and skilled in the fundamentals of 3D printing and would be able to advocate on behalf of the innovation technology and production tool. The event included training with the aid of resources housed in the College of Engineering and Technology. The goal of this initiative was to begin developing a pool of 3D printing advocates who are also economic development and regional transformation advocates. The event announcement - a flyer - appears in Appendix A and depicts the event's goals and agenda.

At the onset of the summer of 2014, the announcement of three-day 3D printing event was conveyed by means of the flyer. The announcement and subsequent follow-ups yielded eight viable participants:

- Technology Support Analyst, School of Medicine;

- undergraduate student working with a faculty member, Surgical Oncology Department; 
- retired associate dean, who is still engaged and active in a part-time capacity, College of Business;

- faculty member, Technology Systems Department;

- Technology Transfer Fellow, Office of Technology Transfer;

- faculty member, Department of Engineering;

- faculty member, institution's library;

- Tech Support Specialist, institution's library.

Due to a situation beyond their control, one participant had to withdraw from the event before it began.

The participants were first introduced to the additive manufacturing resources, capabilities, capacities, and products that could be produced. They were then introduced to several processes underway, including the one with which they would be engaged during the balance of the event. The introduction also included supervised processing and post-processing. Once a level of participant hands-on confidence with 3D printing was achieved, they were provided the opportunity to process canned products, which they could have personalized, and then 3D print the designs they developed. During the end of the last session of the event, the participants were administered a post-event poll to, on a 1-4 scale, gage their satisfaction with the event and to ascertain their plans for the use of the knowledge and skills gained from the event - see Appendix B. Generally speaking, all the participants were very satisfied with their event experience. The descriptive statistics that characterize the participants' level of satisfaction is depicted in Figure 1.

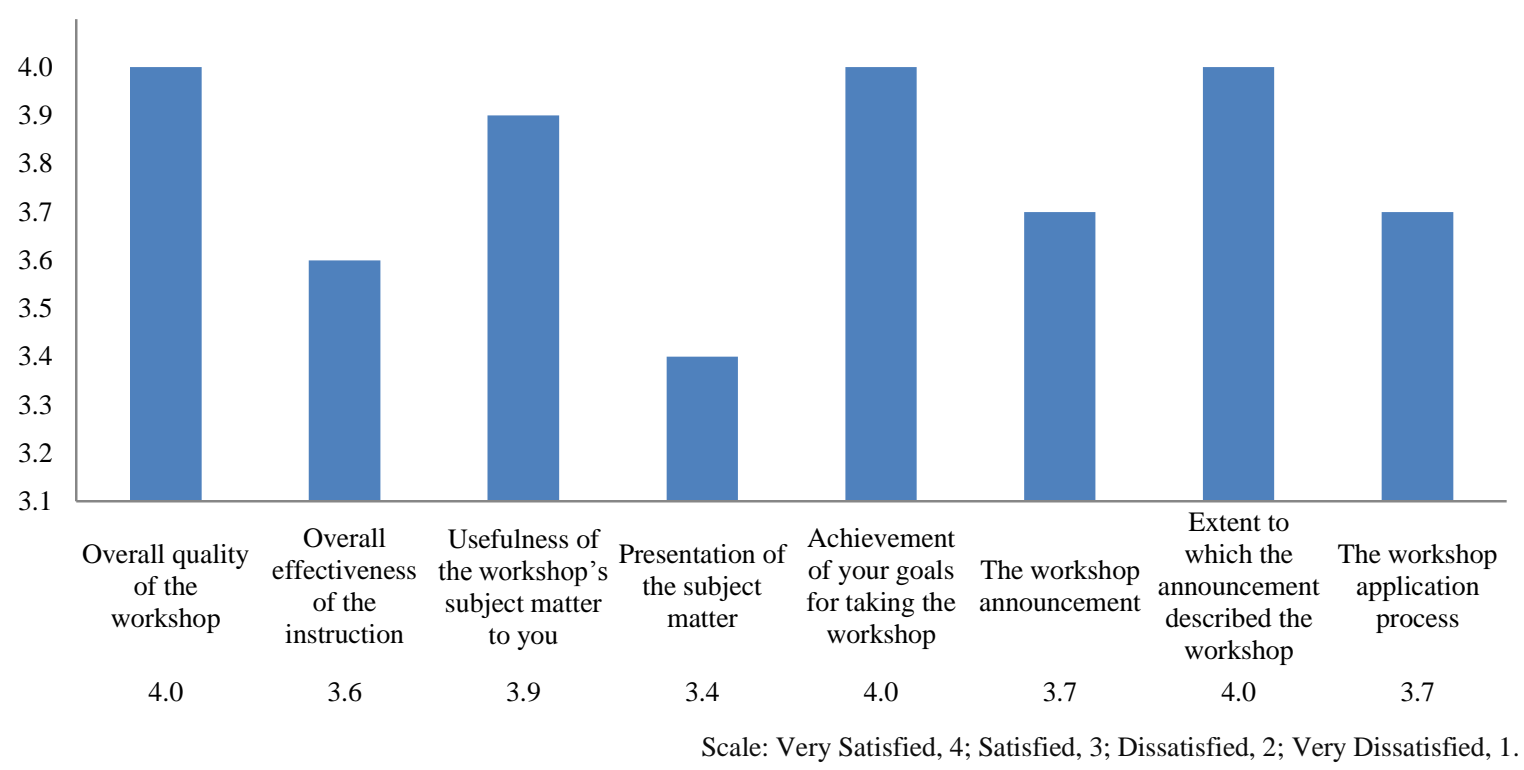

Figure 1: Level of satisfaction with the 3-day event. 


\section{Collaboration with Library}

Libraries, more and more frequently referred to as information or knowledge centers, are probably some of the most accessible facilities on university campuses. Most are accessible close to if not 24 hours a day and almost 365 days a year. The research tends to suggest that the campus library would be one of the better places to house equipment intended to improve accessibility to additive manufacturing.

Following a meeting with the chief administrator of the campus' library and selected library staff members, a small room was made available in the library to the authors.

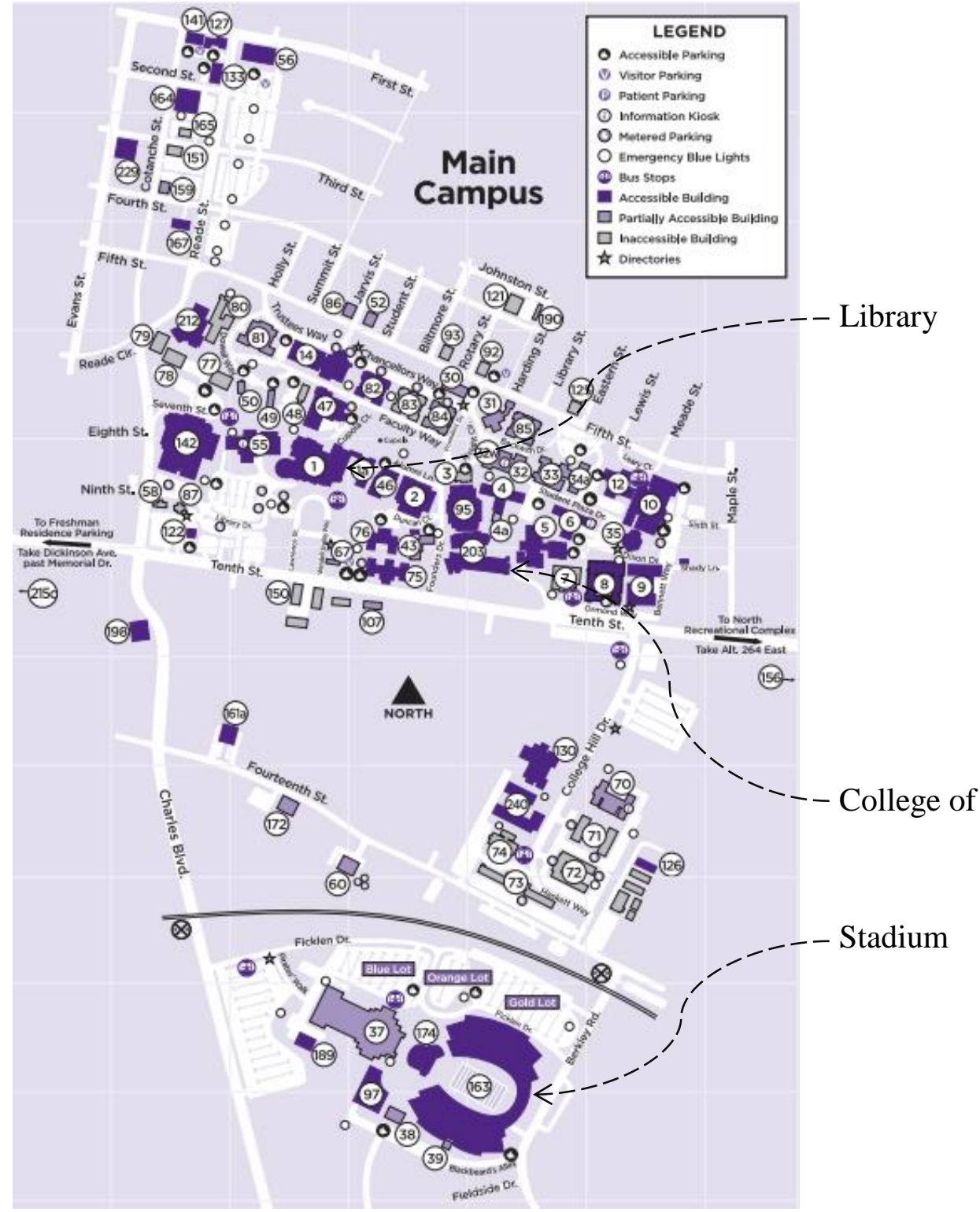

Figure 2: Campus map depicting the location of key structures. 
The campus map is depicted in Figure 2 with the location of the library, the College of Engineering and Technology, and the stadium identified. Figure 3 depicts the location of the 3D printing lab, which is located on the $2^{\text {nd }}$ floor of the library. In addition to housing library stacks and the $3 \mathrm{~d}$ Printing Lab, the second floor houses the library's Teaching Resource Center (TRC) and the library's administrative offices (ADM). Being housed with these library entities is considered a boon for the initiative as it improves visibility.

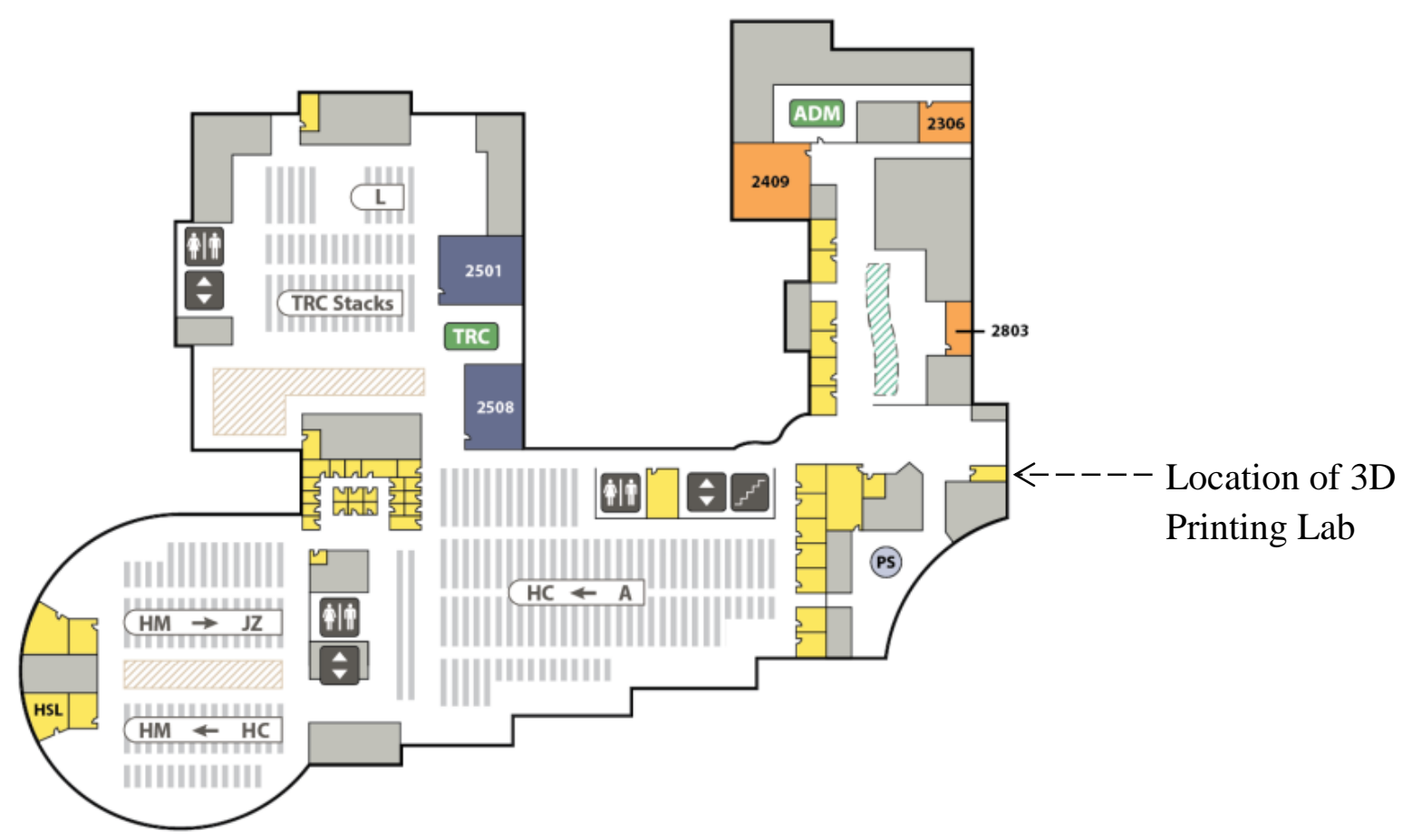

Figure 3: Second floor plan of the library with the location of the 3D printing lab identified.

In the fall of 2014, industrial grade additive manufacturing equipment was relocated to this location. In addition, personnel were trained on the equipment and technology. It is anticipated that as additional advocates are trained and educated, additional engagement and outreach initiatives will be deployed to meet the ever increasing anticipated demand for access to additive manufacturing technology. At present, key is the sustainability of the engagement and outreach initiatives.

To support the initiative, which is articulated in Figure 4(a) and whose goal is to improve accessibility to additive manufacturing, the initiative was able to negotiated the use of a stillserviceable monochrome ZPRINTER ${ }^{\circledR} 310$ PLUS 3D printer, originally intended to be sent to surplus. Figure 4 (b) depicts the 3D printer and associated equipment.

Introduced to the market in 2005, the ZPRINTER $® 310$ PLUS is an entry-level, powder based, $300 \times 450$ dpi resolution 3D printer $^{8}$. Figures 4(c) and 4(d) depict the machine in operation and a sample 3D printed part produced during a training session. 


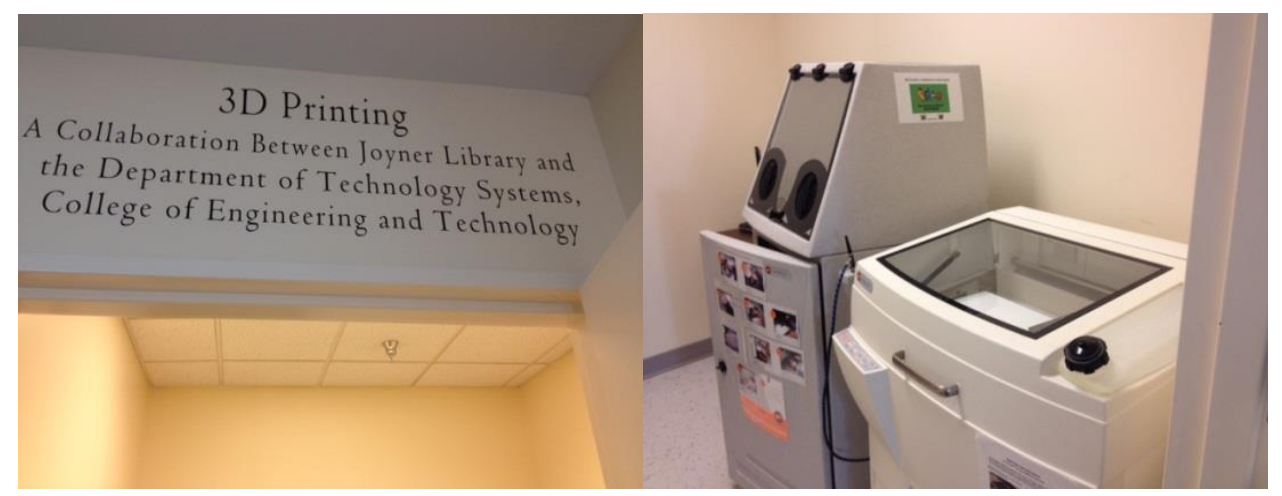

Figure 4(a)

Figure 4(b)

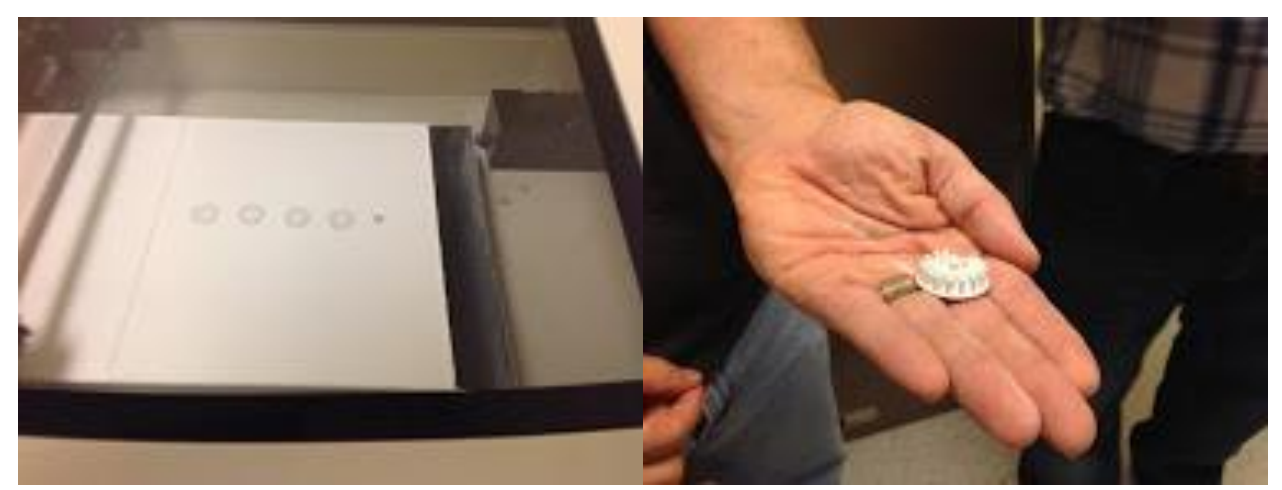

Figure 4(c)

Figure 4(d)

Figure 4: Collaborative 3D printer lab and equipment.

On December 12, 2014 a 1 hour-long workshop was conducted to provide ten library staff members with an overview of 3D printing and the collaborative effort. The participants were administered a post-workshop survey to gage their satisfaction with the workshop. Generally speaking, all the participants were satisfied with their workshop experience. The summary data are depicted Figure 5.

In addition, their comments on the post workshop survey included the follow:

- "More organized presentation. think about attending a larger workshop"

- "I would like to go to advanced workshop. I think I wanted a more in-depth(probably the one offered over a few day period)"

- "Yes, I would like to attend an advanced workshop"

- "Very interesting, would like to be contacted about the next date workshop id available.

- "Interested in attending Summer Workshop"

- "Can't wait for the next step!"

- "interested in attending advanced workshop"

Seven of the participants indicated an interest in attending an advanced workshop, which the authors' anticipate offering during summer of 2015. 


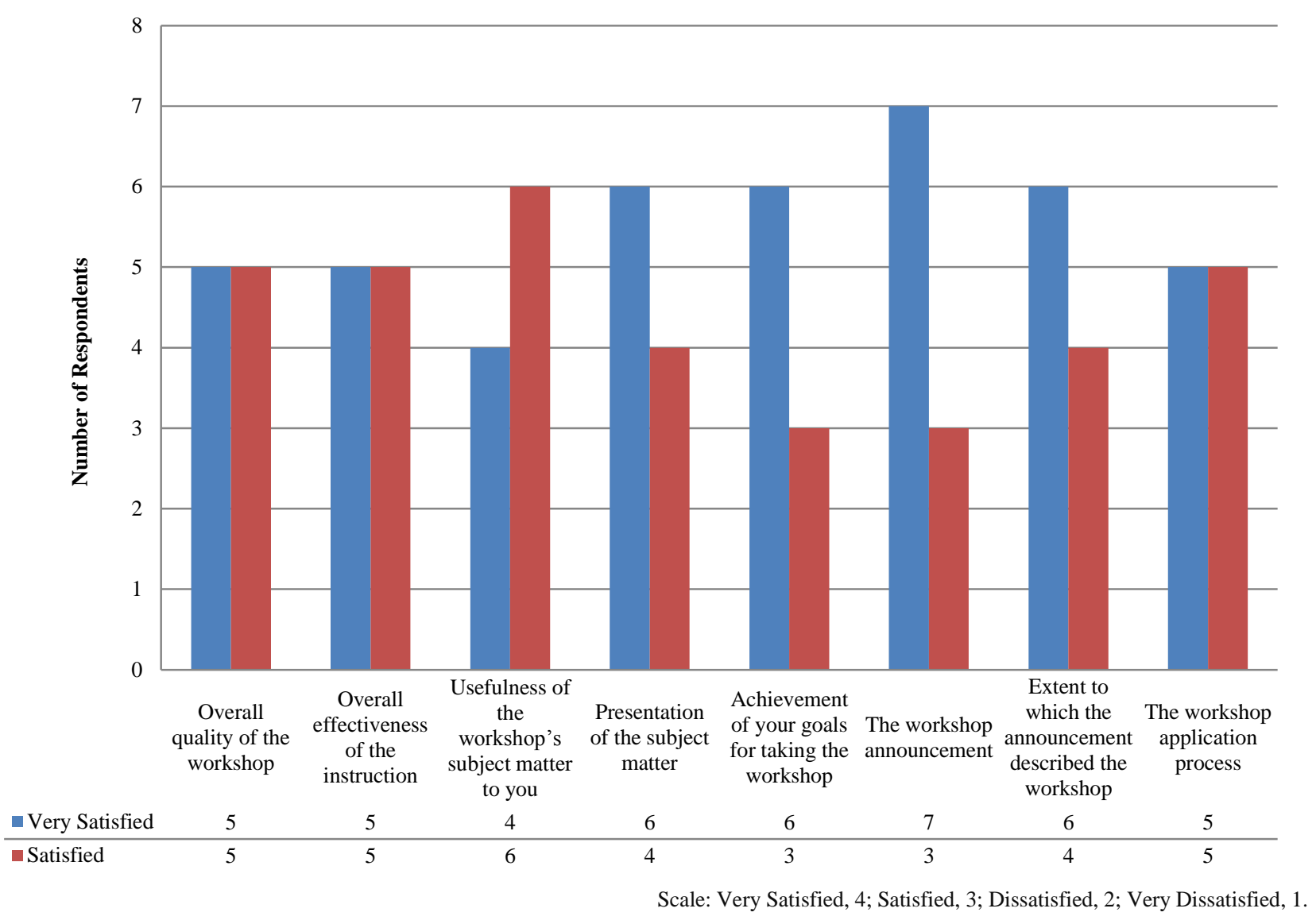

Figure 5: Level of satisfaction with the 1-hour workshop.

\section{"Vending Machines"}

In order to continue fostering additive manufacturing engagement and outreach with the aid of 3D printing, the authors are exploring opportunities to deploy additive manufacturing "vending machines" as part of greater community engagement model ${ }^{9}$. Envisioned is the deployment of these machines at strategic locations across campus, including the library and the football stadium. The campus map is depicted in Figure 2 with the location of the library, the College of Engineering and Technology, and the stadium identified.

Figure 6 depicts two additive manufacturing vending machines that are available. Figure 6(a) depicts "Innovation Station", a 3D printing vending machine developed by the University of Texas at Austin ${ }^{10}$. Figure 6(b) depicts "DreamVendor", developed by Virginia Tech University ${ }^{11}$.

Figure 7 depicts the vision of the anticipated process flow of user and vending machine interaction. Visit will be made to campuses that have integrated vending machine technologies to gain valuable insights and to gauge the effectiveness on how the technologies are integrated with their constituents. Validation of the process flow will take place following the visits. It is anticipated that plans will be solidified by the spring of 2016. 


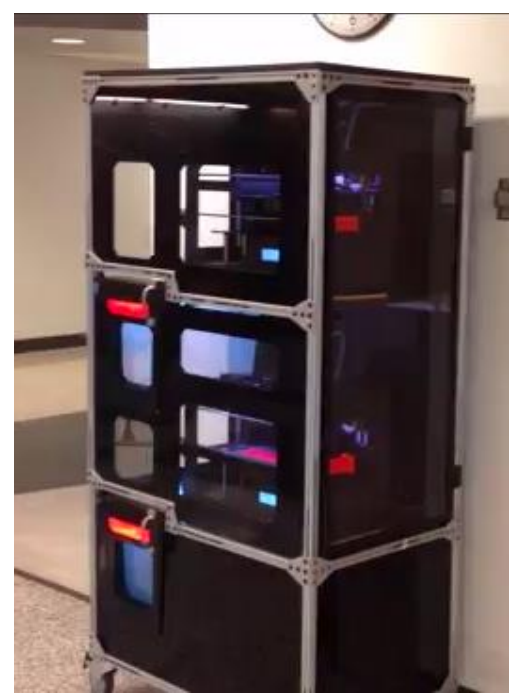

Figure $6(\mathrm{a})^{10}$

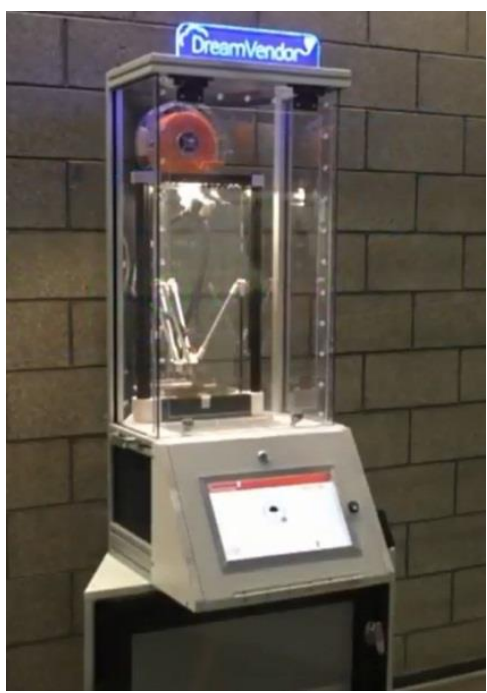

Figure 6(b) ${ }^{11}$

Figure 6: 3D printing vending machines.

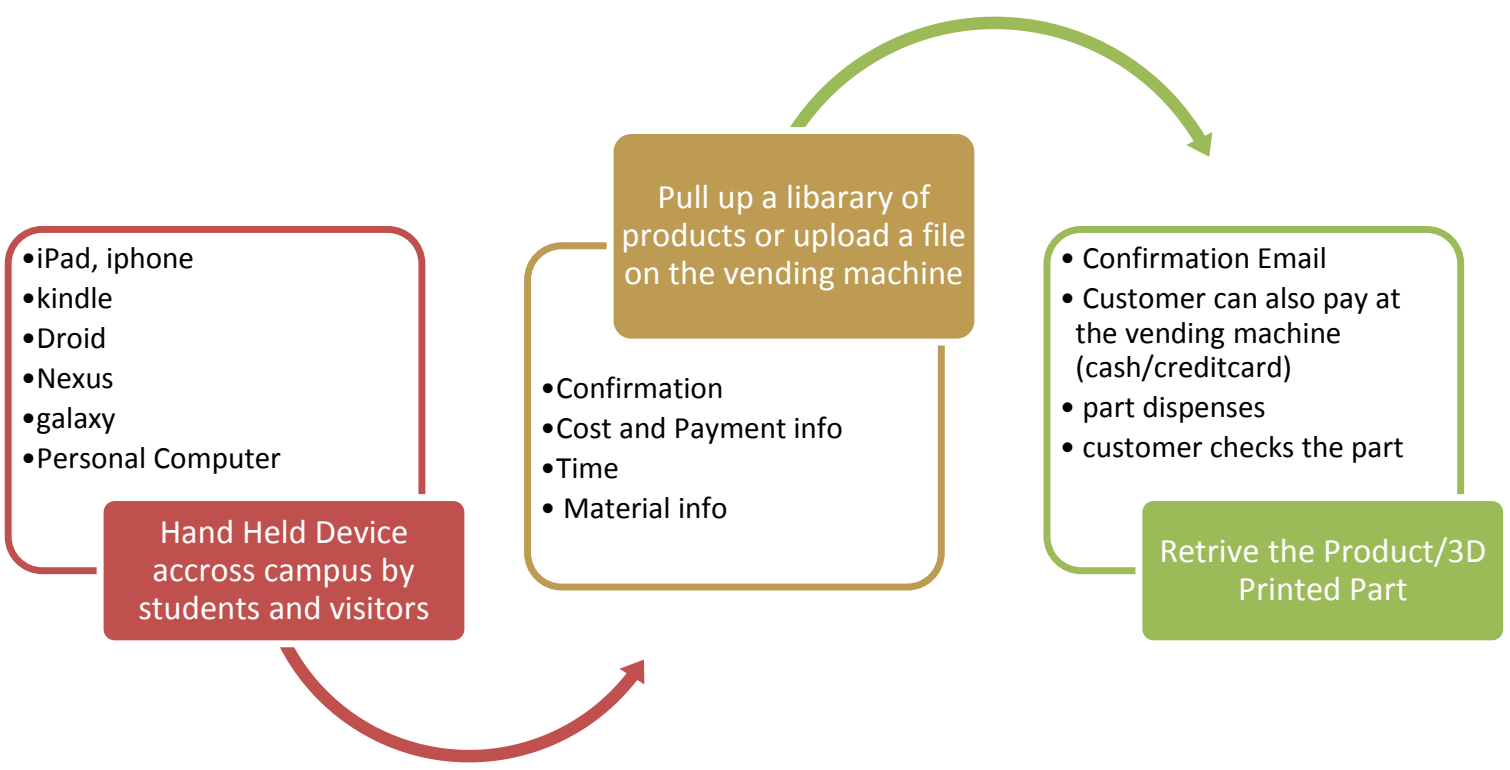

Figure 7: Anticipated process flow of user and vending machine interaction.

\section{Summary}

During summer 2014, a three-day 3D printing event that focused on 3D printing was developed and deployed. The event included training with the aid of resources housed in the College of Engineering and Technology. As the results suggest, all the participants were very satisfied with their event experience. The goal of this event was to begin developing a pool of 3D printing advocates who are also economic development and regional transformation advocates. In the fall of 2014, industrial grade additive manufacturing equipment was relocated to a more public 
facility and one in which members of the community would have greater access to the technology - the campus library. In addition, personnel were trained on the equipment and technology. At the end of the semester, a one hour workshop was conducted to give other library personnel an overview of 3D printing and the collaborative effort. The workshop participants were administered a post-workshop survey to gage their satisfaction with the workshop. The data suggest that the participants were satisfied with their workshop experience. Seven participants indicated their interest in attending an advanced workshop, which the authors anticipate offering during summer 2015. During this workshop, it is anticipated that selected advocates and other personnel with an interest in additive manufacturing will be paired with external constituents from industry, innovation hubs, non-profits, and other academic institutions. The deployment of additive manufacturing "vending machines" is also being explored as part of a greater community engagement model. It is anticipated that this initiative will be solidified by the spring of 2016.

\section{Conclusions}

Delivering instruction to students who become major contributors to business and industry is one of engineering technology's strong suits. It can also play a role in delivering instruction on additive manufacturing's role in stimulating economic development, regional transformation, and domestic competitiveness. This role has been facilitated by the drop in cost for additive manufacturing systems and the increase in availability of technological options. As a result, 3D printing has become a viable engagement and outreach tool for stimulating economic development, regional transformation, and domestic competitiveness.

Additional 3D printing engagement and outreach initiatives are underway and others are in the planning stages. These initiatives include the delivery of introductory and longer, in-depth 3D printing workshops, additional collaborative efforts with the campus library to offer 3D printing services, and the deployment of 3D printing vending machines. Moreover it is envisioned that students in the additive manufacturing course will participate in the execution of these ongoing and future endeavors. The experiences garnered by these students through the interactions with the affected constituents will enrich their learning experiences, which they will carry with them in their professional careers.

\section{Acknowledgement}

The authors wish to express their appreciation for the encouragement and financial support provided by their department chair and college dean. The work completed thus far is a reality because of them. The authors would be remiss if they did not acknowledge the contributions made by their many students. Their patience with us has resulted in the more extensive deployment of additive manufacturing and its used by local businesses and industry. 


\section{Bibliography}

1. Kensinger, L. (2014). Deputy Secretary Newhouse discusses economic impacts of 3D printing and additive manufacturing at expo. Retrieved from http://www.newpa.com/newsroom/deputysecretary-newhouse-discusseseconomic-impacts-3d-printing-and-additive-manufacturingexpo

2. White House. (2013). President Barack Obama's state of the union address-As prepared for delievery. Retrieved from http://www.whitehouse.gov/the-press-office/2013/02/12/presidentbarack-obamas-state-unionaddress

3. Ramaley, J. A., and Zia, L. (2005). "The real versus the possible: Closing the gaps in engagement and learning." Retrieved from http://pdxscholar.library.pdx.edu/cgi/viewcontent.cgi?article=1004\&context=pubadmin_fac

4. Hoy, M B. (2013). "3D printing: Making things at the library." Medical reference services quarterly. Retrieved from http://www.tandfonline.com/doi/abs/10.1080/02763869.2013.749139\#.VM059C6gxdM

5. Scalfani, V. F. and Sahib, J. (2013) "A model for managing 3D printing services in academic libraries." Issues in Science and Technology Librarianship. Retrieved from http://www.istl.org/13-spring/refereed1.html

6. Colegrove, P. (2014). "Making It Real: 3D Printing as a Library Service." Educause Review Online. Retrieved from http://www.educause.edu/ero/article/making-it-real-3d-printing-library-service

7. Pryor, S. (2014). "Implementing a 3D Printing Service in an Academic Library." Journal of Library Administration. Retrieved from http://www.istl.org/14-fall/refereed3.html

8. 3D Systems. (2005). Z Corporation raises 3D printing quality and affordability standard with ZPrinter 310 Plus. Retrieved from http://www.3dsystems.com/press-releases/z-corporationraises-3d-printing

9. Williams, Christopher B., Amelia M. Elliott, David Lee McCarthy, and Nicholas Alexander Meisel. "3D Printing Vending Machine." U.S. Patent Application 14/214,116, filed March 14, 2014. Retrieved from http://www.google.com/patents/US20140288699

10. The Innovation Station. Retrieved from https://innovationstation.utexas.edu/

11. Welcome to the DreamVendor. Retrieved from http://www.me.vt.edu/dreams/dreamvendor/ 
Appendix A. 3D printing announcement and schedule-summer 2014.

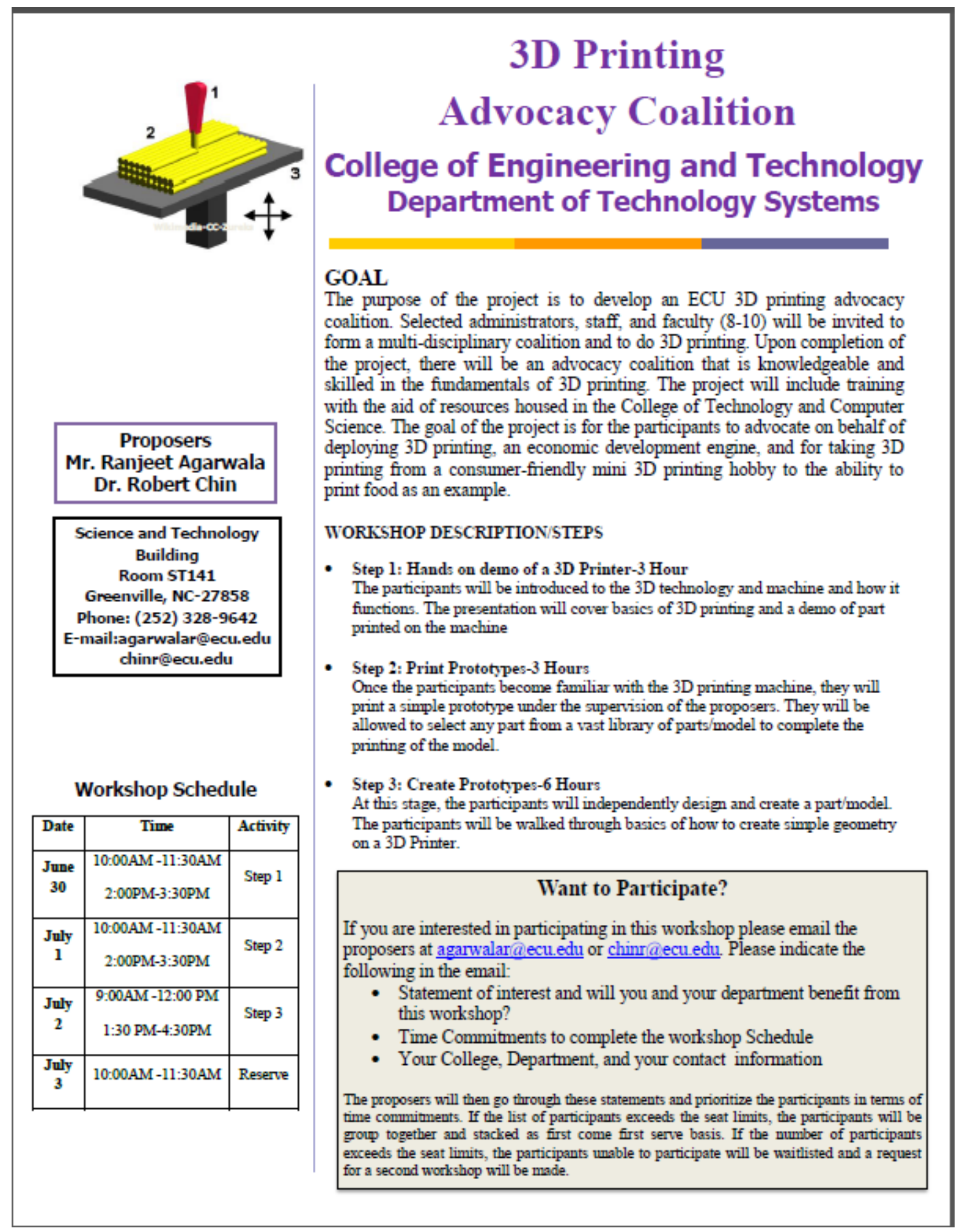


Appendix B. 3D printing post event survey.

3D Printing Post Workshop Poll Name (optional)

We make every attempt to improve all that we do. To that end, we'd appreciate it if you would respond to the following items with respect to the 3D Printing Workshop you just completed.

Directions: Rate the following items with respect to the workshop you just completed by checking the respective boxes:

\begin{tabular}{|c|c|c|c|c|}
\hline & $\begin{array}{l}\text { Very } \\
\text { Satisfied }\end{array}$ & Satisfied & Dissatisfied & $\begin{array}{l}\text { Very } \\
\text { Dissatisfied }\end{array}$ \\
\hline Overall quality of the workshop & $\square$ & $\square$ & $\square$ & $\square$ \\
\hline Overall effectiveness of the instruction & $\square$ & $\square$ & $\square$ & $\square$ \\
\hline Usefulness of the workshop's subject matter to you & $\square$ & $\square$ & $\square$ & $\square$ \\
\hline Presentation of the subject matter & $\square$ & $\square$ & $\square$ & $\square$ \\
\hline Achievement of your goals for taking the workshop & $\square$ & $\square$ & $\square$ & $\square$ \\
\hline The workshop announcement & $\square$ & $\square$ & $\square$ & $\square$ \\
\hline Extent to which the announcement described the workshop & $\square$ & $\square$ & $\square$ & $\square$ \\
\hline The workshop application process & $\square$ & $\square$ & $\square$ & $\square$ \\
\hline
\end{tabular}

Please suggest how we can improve upon the aforementioned if you were less than satisfied:

Directions: Respond to the following items with respect to the workshop you just completed -tell us about:

What you liked best about the workshop:

The one thing that could be improved upon or we should change:

The most useful tips, techniques, or skills you're taking away from this workshop:

The actions you will take in the next 45 days ( 6 weeks) to apply what you've leamed:

How you will measure the success of your actions:

Those at ECU, by name-student(s), staff, or faculty member(s) - who might be interested in or benefit from this workshop:

Any additional comments: 